http://journal.nafo.int

J. Northw. Atl. Fish. Sci., Vol. 19: 21-29

\title{
Optimal Management of the Iceland-Greenland Transboundary Cod Stock
}

\author{
Steen Christensen \\ Danish Institute of Fisheries Economics Research \\ South Jutland University Centre, Niels Bohrs Vej 9 \\ DK-6700 Esbjerg, Denmark \\ and \\ Hans Lassen \\ Danish Institute for Fisheries Research \\ Charlottenlund Slot, DK-2920 Charlottenlund, Denmark
}

\begin{abstract}
Atlantic cod (Gadus morhua) in Icelandic waters, in the Davis Strait, and east and southeast of Greenland is a transboundary stock which inhabits both the Greenlandic and the Icelandic Fishing Zones. In some years large numbers of eggs, larvae and juvenile cod are carried from the spawning grounds in Icelandic waters to Greenland waters where they settle and form the basis for a fishery in the following years. The Icelandic component of the West Greenland cod stocks displays homing behaviour and returns to the Icelandic spawning grounds when they reach maturity, at the age of about 5 years. In the present paper, an optimization scheme for this transboundary cod stock is suggested, including a standard bioeconomic model of the fisheries and simple game theory. Simulations indicate that if the resource is considered to be an entirely migratory resource, both the total catch volume and the net present value (NPV) of the resource rent are maximized when all landings of the stock are made from the Icelandic zone. The results are discussed relative to year-class size and different management consideration for cooperation among the parties.
\end{abstract}

Key words: Bioeconomy, cod, Greenland, Iceland, management, transboundary resource

\section{Introduction}

The significant fishery of the present century on cod (Gadus morhua) off West Greenland at West Greenland was probably based on a cod stock initiated from eggs, larvae and 0 -groups carried from Iceland by the Irminger Current during the 1920s (Cushing, 1982). During the warm period of 1915-65, several good year-classes increased the Davis Strait cod biomass, and led to a rise in the offshore fishery (Fig. 1) which persisted into the 1950 s and 1960s, because fishing was reduced during World War II. This offshore cod stock eventually comprised a local spawning population sustained by repetitive inflows from Iceland at irregular intervals. The relative strength of the Icelandic component is believed to have been of variable significance and perhaps correlated to the relative spawning success in Iceland and Greenland, and to the strength of the Irminger Current (Buch et al., 1994). Increased catches in the 1960s declined the stock and affected the population structure which became dominated by one or just a few year-classes.
Comprehensive tagging studies in West Greenland indicate, that cod of Icelandic origin migrate back to the Icelandic spawning grounds at maturity, and that the emigration rate has decreased after World War II (Hansen et al., 1935; Rasmussen, 1957). This indication of reduced inflow of larvae from Iceland is supported by meteorological and hydrographic information suggesting that the period of warming peaked during the 1950s and was succeeded by the present colder period with a less strong Irminger Current. Therefore the fishery quickly collapsed when local West Greenland recruitment failed at the onset of the colder period in the mid-and late-1960s, probably due to low sea temperatures at the time of spawning (Buch et al., 1994).

In the late-1970s and in the beginning of the 1980 s, the fishery was partly increased again but, as it was based almost entirely on the 1973 yearclass, it subsequently declined as this year-class was reduced. Similarly, the 1984 year-class estimated at 380 million 3 -year-old fish, and the 1985 year-class (1/5 of the 1984 year-class), 


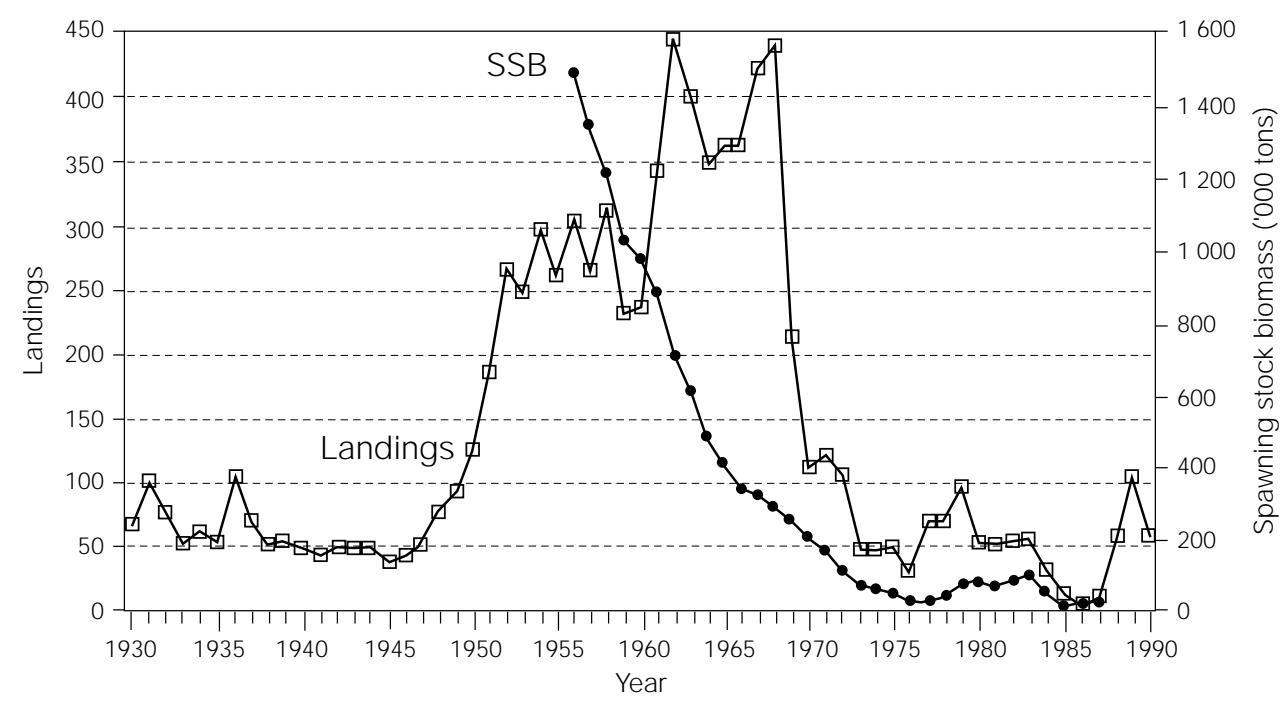

Fig. 1. Spawning stock biomass, SSB, and landings of Atlantic cod in NAFO Subarea 1. (Source: NAFO, 1986-1991; Cushing, 1982; Horsted, MS 1990)

potential future offshore cod fishery at West Greenland is therefore likely to be based on a single cohort initiated from inflows of eggs, larvae and 0 groups from lceland rather than from local spawning. A substantial part of such a stock must be expected to home to Iceland at maturity.

Consequently, management of the next Icelandic-Greenlandic cod stock may be regarded as management of a transboundary resource shared between two states (Munro, 1991). The two countries may have different management objectives. As history suggests, a Greenlandic spawning biomass is not necessarily guaranteed by the appearance of Icelandic immigrants. A rational management objective from Greenland's point of view would therefore be to maximize the outcome of the cohort before emigration takes place. Depending on the perception of the social discount rate, this strategy might be considered growth overfishing, from the point of view of the co-owner, Iceland.

In this context, it is the aim of the present paper to discuss whether cooperation between the joint owners, Greenland and Iceland, may be advantageous, or whether independent management of their individual shares of the resource may be equally good.

A bioeconomic model of a two area system (Fig. 2 ) is applied. The cod stock off Iceland (area 1) is regarded as a self sustained stock. It is assumed that a cod stock at Greenland (area 2) is based solely on inflows of larvae and juveniles from Iceland and that no local offshore spawning takes place.
The cod stock at Greenland constitutes the basis for a fishery in that area until the age of maturity when they migrate back to Iceland. At Iceland the immigrating cods are exposed to a fishery directed towards the stationary stock component.

Analyses are presented for the scenario a) where a single strong year-class is recognized by both parties before an agreement is entered, and b) where a long-term agreement is established under uncertainty with regard to the future state of the resource. Maximizing the net present value (NPV) of the resource rent was chosen as the economic objective, whereas maximizing the catch volume was chosen as the biological objective.

\section{The Model}

The objective function to be maximized is the present-value of the resource rent, $\pi$. This function can be expressed as:

$$
\begin{aligned}
\operatorname{Max} \pi= & \sum_{\mathrm{t}} \mathrm{TR}_{\mathrm{t}}\left(\mathrm{p}_{\mathrm{Gr}, \mathrm{a}}, \mathrm{Y}_{\mathrm{Gr}, \mathrm{a}}, \delta_{\mathrm{Gr}}, \mathrm{P}_{\mathrm{Is}, \mathrm{a}}, \mathrm{Y}_{\mathrm{Is}, \mathrm{a},} \delta_{\mathrm{Is}}\right) \\
& -\mathrm{TC}_{\mathrm{t}}\left(\mathrm{C}_{\mathrm{Gr}}, \mathrm{D}_{\mathrm{Gr}}, \delta_{\mathrm{Gr}}\right)
\end{aligned}
$$

where $\mathrm{TR}_{\mathrm{t}}=$ total revenue at time $\mathrm{t}$,

$\mathrm{TC}_{\mathrm{t}}=$ total costs at time $\mathrm{t}$,

$\mathrm{Y}_{\mathrm{Gr}, \mathrm{a}}=$ total Greenlandic catch-at-age a (weight),

$\mathrm{Y}_{\mathrm{Is}, \mathrm{a}}=$ total Icelandic catch-at-age a (weight),

$\mathrm{P}_{\mathrm{Gr}, \mathrm{a}}=$ sales price in Greenland for cod-at-age a ( $\mathrm{kg}$ live weight),

$\mathrm{P}_{\mathrm{Is}, \mathrm{a}}=$ sales price in Iceland for codat-age a (kg live weight),

$\delta_{\mathrm{Gr}}, \quad=$ social discount rate in Greenland, 


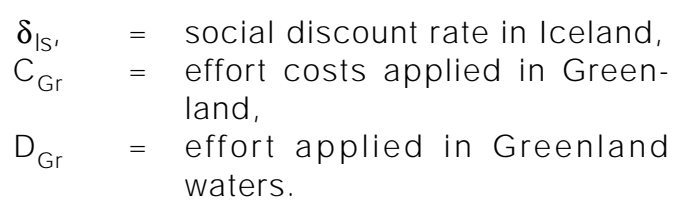

The yield $Y$ in the objective function (1) is calculated by a modified Thompson and Bell yieldper-recruit modal (Thompson and Bell, 1934). This dynamic pool model can be expressed as:

$$
\mathrm{Y}=\sum_{\mathrm{b}} \sum_{\mathrm{a}} \mathrm{N}_{\mathrm{b}, \mathrm{a}} \times\left(1-\exp \left(-\mathrm{Z}_{\mathrm{b}, \mathrm{a}}\right)\right) \times \frac{\mathrm{F}_{\mathrm{b}, \mathrm{a}}}{\mathrm{Z}_{\mathrm{b}, \mathrm{a}}} \times \mathrm{W}_{\mathrm{b}, \mathrm{a}}
$$

where $\mathrm{N}_{\mathrm{b}, \mathrm{a}}=$ number of cod at age $\mathrm{a}$ in area $\mathrm{b}$,

$\mathrm{W}_{\mathrm{b}, \mathrm{a}}=$ average weight of cod at age $\mathrm{a}$ in area $b$,

$\mathrm{Z}_{\mathrm{b}, \mathrm{a}}=$ total mortality rate at age $\mathrm{a}$ in area b,

b $\quad=\operatorname{area}(1$ and 2$)$.

The present value, PV, of the revenue of each fishery is calculated by:

$$
P V_{b}=\sum_{t} \sum_{a} Y_{b, a} \times \frac{P_{b, a}}{\left(1+\delta_{b}\right)^{t}}
$$

The total mortality rate in the Greenlandic stockat-age, $Z_{G r, a}$, is calculated as:

$$
Z_{G r, a}=F_{G r, a}+M_{G r, a}+E_{G r, a}
$$

where $F_{G r, a}=$ fishing mortality rate in Greenland at age a,

$\mathrm{M}_{\mathrm{Gr}, \mathrm{a}}=$ natural mortality rate in Greenland at age a,

$\mathrm{E}_{\mathrm{Gr}, \mathrm{a}}=$ emigration rate in Greenland at age a.

Assuming that the emigration from Greenland waters is a spawning migration initiated by maturity, the age dependent emigration rates are calculated by:

$$
E_{G r, a}=-\ln \left(1-S_{l s, a}\right)
$$

where $\mathrm{S}_{\mathrm{Is}, \mathrm{a}}=$ the Icelandic maturity ogive at age a.

The Icelandic stock has an emigration rate of zero, i.e.:

$$
Z_{\text {Is }, a}=F_{l s, a}+M_{l s, a}
$$

The number of cod in Greenland at age a, $\mathrm{N}_{\mathrm{Gr}, \mathrm{a}}$, is calculated as:

$$
\mathrm{N}_{\mathrm{Gr}, \mathrm{a}}=\mathrm{N}_{\mathrm{Gr}, \mathrm{a}-1} \times \exp \left(-\mathrm{Z}_{\mathrm{Gr}, \mathrm{a}-1}\right)
$$

whereas the number of cod in Iceland at age a, $\mathrm{N}_{\mathrm{ls}, \mathrm{a}}$ must be calculated by the differential equation:

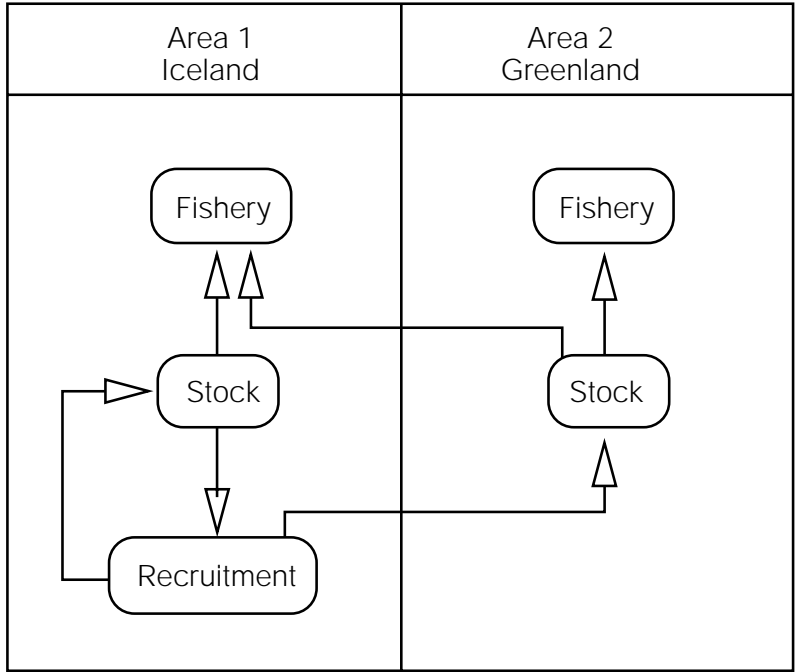

Fig. 2. Schematic of stock dynamics applied to the bioeconomic fishery model of the IcelandGreenland transboundary cod stock.

$$
\frac{\partial \mathrm{N}_{\mathrm{ls}, \mathrm{a}}}{\mathrm{dt}}=\mathrm{N}_{\mathrm{ls}, \mathrm{a}} \times\left(-\mathrm{Z}_{\mathrm{ls}, \mathrm{a}}\right)+\mathrm{N}_{\mathrm{Gr}, \mathrm{a}} \times \mathrm{E}_{\mathrm{Gr}, \mathrm{a}}
$$

to incorporate the immigrants from Greenland also. Equation (8) has the solution:

$$
\begin{aligned}
& N_{\text {ls, } a}=N_{\text {ls, } a-1} \times \exp \left(-Z_{\text {ls, a-1 }}\right)+\frac{E_{G r, a-1} \times N_{G r, a-1}}{Z_{\text {ls, } a-1}-Z_{G r, a-1}} \\
& \times\left(\exp \left(-Z_{\text {Gr,a-1 }}\right)-\exp \left(-Z_{\text {ls, a-1 }}\right)\right)
\end{aligned}
$$

which can be derived by mathematical computer software (see e.g. Wolfram, 1991) or manually as described e.g. by Anon. (1968).

In both areas, the fishing mortality rate-at-age, $F_{a}$, is assumed to be proportional to effort, $D$, and influenced by an age dependent gear selection, $\mathrm{S}_{\mathrm{a}}$, i.e.:

$$
F_{a}=S_{a} \times D
$$

It is the intention of the present paper only to discuss the trade value of a single cohort of cod migrating back to Iceland. Therefore, it is assumed that the fishery of Iceland is optimized on a longterm basis, and that no additional effort is applied by Iceland to catch the immigrants. Consequently, in all calculations the effort applied by Iceland is regarded as a constant, and the marginal cost to catch the immigrants is zero.

With respect to Greenland, the effort and costs are allowed to vary in order to optimize the yield. The cost of the effort applied in Greenland, TC of the objective function (1), is calculated by:

$$
\mathrm{TC}=\sum_{\mathrm{t}} \mathrm{C}_{\mathrm{Gr}} \times \frac{\mathrm{D}_{\mathrm{Gr}, \mathrm{t}}}{\left(1+\delta_{\mathrm{Gr}}\right)^{\mathrm{t}}}
$$


where $\mathrm{C}_{\mathrm{Gr}}$ is the cost-per-unit-fishing mortality applied by the Greenland fishery.

\section{Materials and Methods}

The age dependent input values of selection parameters $(\mathrm{S})$, natural mortality ratios $(\mathrm{M})$, average weights (w), and the maturity ogives, proportional mature ( $\mathrm{s}$ ), are presented in Table 1. As demonstrated, there is considerable difference between the weight-at-age of cod caught in Greenland and in Iceland. At least two factors may account for this difference. First, the environmental stress (e.g. lower temperature) at Greenland may be more pronounced than at Iceland. This could lead to a reduced growth rate. Secondly and maybe more importantly, the observed discrepancy may result from the migrating behaviour of the mature component of the stock at Greenland. Assuming that maturity is a function of size rather than age, emigration of mature individuals would reduce the average weight-at-age of the remaining population.

In the present study, a weight-at-age array, based on surveys conducted in NAFO Subarea 1 (NAFO, 1990), is applied to the cod caught at Greenland. The immigrants caught at Iceland are assumed to follow the growth pattern of the Icelandic cod stock (Anon., MS 1993) but with a lag of one year to account for their life history.

As also demonstrated in Table 1, the maturity rate-at-age is considerably higher at Iceland than at Greenland. Following the same lines of arguments as outlined above with respect to the weight-at-age, this discrepancy may be due to environmental differences or the homing behaviour of the mature part of the stock component at Greenland.

It is assumed that cod emigrate from Greenland at the onset of maturity. Therefore, the estimated migration ratios, calculated by equation (5), are based on the maturity ogives of the Icelandic stock (Table 1).

Based on the principle of opportunity costs, Christensen and Vestergaard (1993) estimated the total cost of one fishing day of a shrimp trawler to be between DKK 42500 and DKK 80000 in 1991, depending on the underlying assumptions about the level of opportunity cost for labour and the level of the real interest rates of capital. As no information on costs in the Greenland trawl fishery for cod has been available for the present study, the economic conditions are assumed to be about the same as in the shrimp fishery. Therefore, DKK 60000 is applied as the total cost for one fishing day for a trawler catching cod and the interest rate at $7 \%$ per year. Based on information about the cod fishery in 1990 (Hovgård, Danish Institute for Fisheries Research, Charlottenlund Slot, Denmark, pers. comm.), the total number of fishing days is roughly estimated at 1000 . Accordingly, the total cost of one year is estimated at DKK 60 million. In 1990, a fishing mortality rate of about 0.5 was estimated to apply to the fully recruited subset of the 1984 year-class. The cost of one fishing mortality unit applied, $\left(\mathrm{C}_{\mathrm{Gr}}\right.$ in equation 11) in this way was estimated at DKK 120 million.

Rough estimates of Greenlandic marked prices in 1991 are applied to the catches of both nations.

TABLE 1. Natural mortality ratios, M, Emigration ratios, E, selection parameters, S, average weights, w, and proportion mature, s, of Atlantic cod (Gadus morhua) at Greenland and Iceland.

\begin{tabular}{|c|c|c|c|c|c|c|c|c|c|}
\hline \multirow[b]{2}{*}{ Age } & \multirow[b]{2}{*}{ S } & \multicolumn{3}{|c|}{ Greenland $^{1}$} & \multirow[b]{2}{*}{ s } & \multicolumn{4}{|c|}{ Iceland $^{2}$} \\
\hline & & $\mathrm{M}$ & w & $E^{3}$ & & S & M & w & s \\
\hline 3 & 0.039 & 0.2 & 0.86 & 0.020 & 0.01 & 0.066 & 0.2 & 1.26 & 0.020 \\
\hline 4 & 0.520 & 0.2 & 0.91 & 0.070 & 0.03 & 0.328 & 0.2 & 1.78 & 0.068 \\
\hline 5 & 1.000 & 0.2 & 1.02 & 0.286 & 0.06 & 0.599 & 0.2 & 2.58 & 0.249 \\
\hline 6 & 1.000 & 0.2 & 1.36 & 0.719 & 0.08 & 0.856 & 0.2 & 3.63 & 0.513 \\
\hline 7 & 1.000 & 0.2 & 2.04 & 1.465 & 0.65 & 1.089 & 0.2 & 4.90 & 0.769 \\
\hline 8 & 1.000 & 0.2 & 2.12 & 2.313 & 0.90 & 1.152 & 0.2 & 6.30 & 0.901 \\
\hline 9 & 1.000 & 0.2 & 2.20 & 3.037 & 0.98 & 1.152 & 0.2 & 7.69 & 0.952 \\
\hline 10 & 1.000 & 0.2 & 2.89 & 3.689 & 1.00 & 1.152 & 0.2 & 9.35 & 0.975 \\
\hline 11 & 1.000 & 0.2 & 3.79 & 5.116 & 1.00 & 1.152 & 0.2 & 10.92 & 0.994 \\
\hline 12 & 1.000 & 0.2 & 5.36 & 3.912 & 1.00 & 1.152 & 0.2 & 12.77 & 0.983 \\
\hline 13 & 1.000 & 0.2 & 5.36 & 4.962 & 1.00 & 1.152 & 0.2 & 14.52 & 0.993 \\
\hline
\end{tabular}

1 Source: Anon., 1991.

2 Source: Anon., 1993.

3 Based on Icelandic maturity ogives. 
A price of DKK 4.5 per $\mathrm{kg}$ live weight is assumed for cod of age 3, 4 and 5, whereas a price of DKK 6.0 per kg live weight is assumed for older cod.

\section{Results}

Three scenarios are presented. Scenario one and two evaluate the situation where a single strong year-class at Greenland is recognized by both parties before an agreement is entered. In scenario one, the local economic optimum for Greenland is estimated in terms of net present-value (NPV) of the resource rent and compared to the joint optimum for Iceland and Greenland. In scenario two, optimality is defined in biological terms and benefits from cooperation are discussed in terms of catch volume.

The third scenario evaluates the situation where the parties want to establish a long-term agreement. Under these conditions, by nature, an agreement must be negotiated without knowledge about future year-class strengths.

\section{Optimum of a Single Strong Year-class}

In the non-cooperative situation, Greenland optimizes its fishery ignoring the impact of the Icelandic catches. If a single strong cohort is of a similar size as the one of 1984 is recognized, the optimal solution for Greenland is to apply a fishing mortality rate at 0.94 and 0.58 , equivalent to 1900 and 1200 fishing days, at ages 4 and 5, respectively. As it is a single cohort which is under consideration, this implies that the optimal solution is to fish in year 4 and 5 only. In all other years the fishing mortality rate on the cohort should be zero. The NPV to Greenland is estimated at DKK 554 million and the value of the Icelandic catches of the immigrants is estimated at DKK 508 million (Table 2).

Figure 3 shows the distribution between Greenland and Iceland of the total NPV of the resource rent of a single cohort in the noncooperative situation as a function of year-class size. It indicates that the resource rent to Greenland

TABLE 2. Net present value of resource rent (million DKK) in scenario one. Non-cooperation: Local optimums for Greenland and Iceland under a non-cooperation management strategy. Cooperation: total net present value of resource rent under cooperation.

\begin{tabular}{lrrr}
\hline \hline & Greenland & Iceland & Total \\
\hline Non-cooperation & 554 & 508 & 1061 \\
Cooperation & 0 & 2713 & 2712 \\
\hline
\end{tabular}

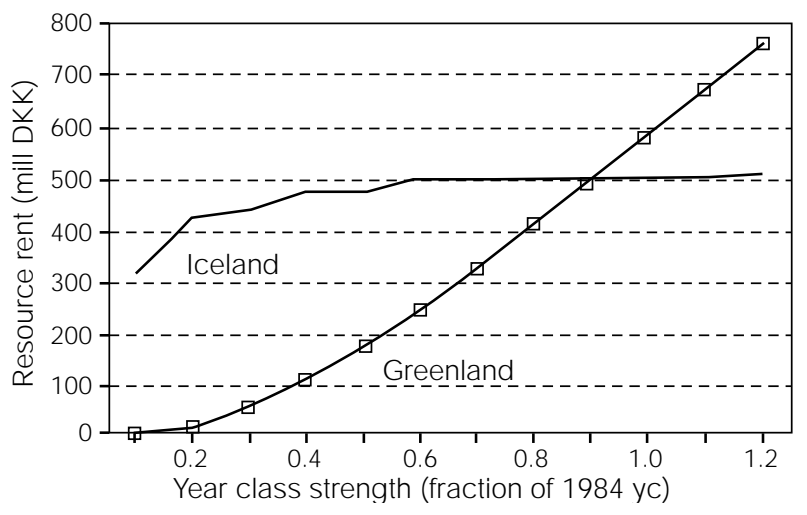

Fig. 3. Distribution of resource rent as a function of year-class strength in the non-cooperative

increases with the size of the year-class. At small year-classes also the resource rent to Iceland increases with year-class size, but from a year-class size to about $40 \%$ of the 1984 year-class, the Icelandic share of the resource rent remains almost constant at about DKK 500 million.

The optimal fishing strategy from a joint Greenlandic-Icelandic point of view is to establish cooperation. In the cooperative situation all fishing must take place in area 2, i.e. in Icelandic waters, to obtain the maximum resource rent. In that case the total NPV is DKK 2.713 billion (Table 2).

Cooperation increases the total NPV of the cohort by DKK 1652 million compared to a noncooperative situation. The NPV to Greenland which is foregone in this case is DKK 554 million, could be considered as a cost to be payed in the joint cooperative model. The excess amount of DKK 1 098 million may be considered as the profit obtained by cooperation. This amount could be distributed between the parties according to their relative bargaining power to obtain pareto-efficiency.

Figure 4 shows the resource rent for the cooperative solution as a function of the year-class strength. It demonstrates how the total resource rent, as well as the surplus resource rent obtained by cooperation, increase with year-class strength.

\section{Maximum Sustainable Yield}

Management advice based on biological parameters only, i.e.

$$
\mathrm{P}_{\mathrm{Gr}}=1, \mathrm{P}_{\mathrm{Is}}=1, \delta_{\mathrm{Gr}}=0, \delta_{\mathrm{Is}}=0 \text { and } \mathrm{C}_{\mathrm{Gr}}=0
$$

is dependent on whether the parties cooperate or not. Without cooperation Greenland will obtain the highest yield by applying a very high effort which, in turn, imposes a decrease in the Icelandic yields (Fig. 5). 


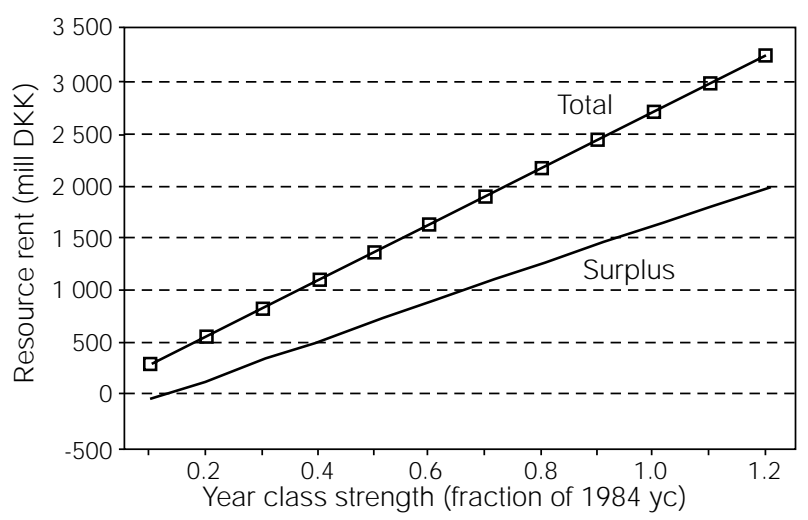

Fig. 4. The total resource rent (million DKK) of Greenland and Iceland (Total) in the cooperative situation and the surplus resource rent obtained by cooperation (Surplus).

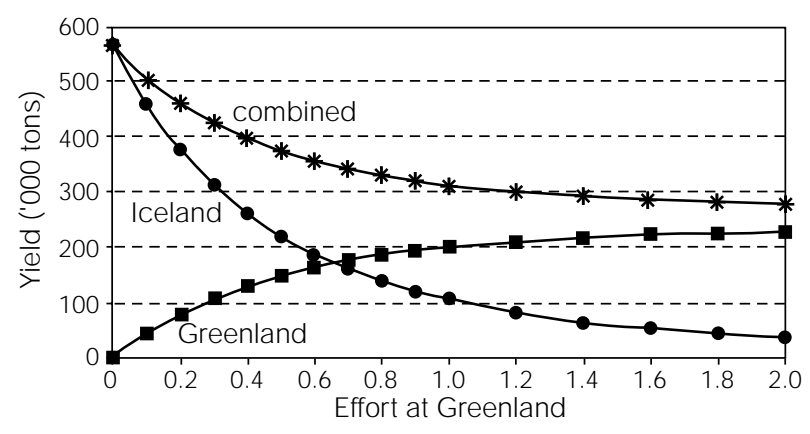

Fig. 5. Yield as a function of effort applied by Greenland. Greenland efforts is relative to effort in 1990 whereas effort by Iceland is assumed constant.

The total maximum yield is obtained by cooperation between the parties. If Greenland ceases fishing entirely, the catches of Iceland will increase to about 600000 tons which is about twice the total yield obtained in the non-cooperative situation.

\section{Long-term Optimum}

If the parties want to establish a long-term agreement, necessarily, it must be negotiated without knowledge about future year-class strengths. Assuming stochastic recruitment, this situation may be considered as a game between two opponents: Iceland, who pays Greenland a fixed amount annually, and Greenland, who then refrains from cod fishing.

In such a game the net revenue from the fishery is dependent on the stochastic distribution of yearclass strengths in the coming years. Therefore, a frequency distribution of year-class strengths was constructed based on the year-classes 1964-86
(Table 3). This frequency distribution, shown in Table 4 , is considered to represent the distribution of yearclass strengths that would be observed in the period for which the agreement is valid.

Assuming equilibrium conditions, i.e. that recruitment is equal to the average recruitment of the period 1967-89, the annual resource rent is estimated at DKK 160 million which can be obtained if the parties cooperate, i.e. the fishing effort in Greenland waters is zero. The Greenland average net revenue in the non-cooperation situation is DKK 35 million, which would be the theoretical minimum for compensating in the scenario where Greenlandic fishing is set to zero.

In a non-equilibrium situation the long-term recruitment estimation is carried out as follows: for each year of the agreement, a year-class strength is sampled from the empirical distribution of yearclasses 1964-86 (age 3). Then two revenues are calculated. The revenue Greenland would get if it adopted the local optimal strategy. Second, the revenue to Iceland in a joint optimal fishing situation less the contribution Iceland would get if Greenland decided to follow its local optimal strategy. These revenues are each aggregated over the entire period of the agreement. The simulation was repeated 1000 times and the resulting cumulative curves of the total revenue to Iceland and to Greenland are shown in Fig. 6 (a 20-year agreement) and in Fig. 7 (a 5-year agreement).

The price for a 20-year agreement is to be discussed based on the curves of Fig. 6. For example, if Iceland pays Greenland DKK 2000 million over 20 years (i.e. DKK 100 million per year) then Greenland, in more than $90 \%$ of the simulations, would have done better by the

TABLE 3. Year-class strength of Atlantic cod (Gadus morhua) in Greenland waters 1967-89, relative to the 1984 year-class. 1984 year-class $=1$ at age 3 in 1987. (Source: Hovgård, Danish Institute for Fisheries Research, Charlottenlund Slot, Denmark, pers. comm.)

\begin{tabular}{llll}
\hline \hline Year & 1960 & 1970 & 1980 \\
\hline 0 & & 0.07 & 0.22 \\
1 & & 0.16 & 0.01 \\
2 & & 0.03 & 0.12 \\
3 & & 0.02 & 0.02 \\
4 & & 0.03 & 0.02 \\
5 & & 0.04 & 0.01 \\
6 & & 0.40 & 0.01 \\
7 & 0.15 & 0.08 & 1.00 \\
8 & 0.16 & 0.08 & 0.13 \\
9 & 0.13 & 0.06 & 0.00 \\
\hline
\end{tabular}


TABLE 4. Net present value of Atlantic cod (Gadus morhua) landings for the transboundary stock, as a function of relative year-class size under cooperation and non-cooperation.

\begin{tabular}{ccccc}
\hline \hline $\begin{array}{c}\text { Year-class strength } \\
\text { relative to 1984 } \\
\text { year-class }\end{array}$ & $\begin{array}{c}\text { Year-class } \\
\text { frequency }\end{array}$ & $\begin{array}{c}\text { Non-cooperation } \\
\text { Greenland net revenue } \\
\text { mill. DKK }\end{array}$ & $\begin{array}{c}\text { Iceland net revenue } \\
\text { mill. DKK }\end{array}$ & $\begin{array}{c}\text { Cooperation } \\
\text { total net revenue } \\
\text { mill. DKK }\end{array}$ \\
\hline 0.0 & 9 & 0 & 0 & 313.9 \\
0.1 & 5 & 0 & 313.9 & 546.6 \\
0.2 & 6 & 12.2 & 421.0 & 819.8 \\
0.3 & 1 & 53.6 & 440.0 & 1093.1 \\
0.4 & 1 & 107.4 & 474.4 & 1366.4 \\
0.5 & 0 & 171.3 & 473.9 & 1639.7 \\
0.6 & 0 & 239.1 & 501.9 & 1912.9 \\
0.7 & 0 & 311.6 & 501.9 & 2186.2 \\
0.8 & 0 & 388.7 & 505.4 & 2459.5 \\
0.9 & 0 & 469.4 & 506.6 & 2717.9 \\
1.0 & 1 & 554.0 & 507.7 & 3006.0 \\
1.1 & 0 & 640.5 & 508.9 & 3279.3 \\
1.2 & 0 & 728.8 & 514.6 & 27.3 \\
\hline
\end{tabular}

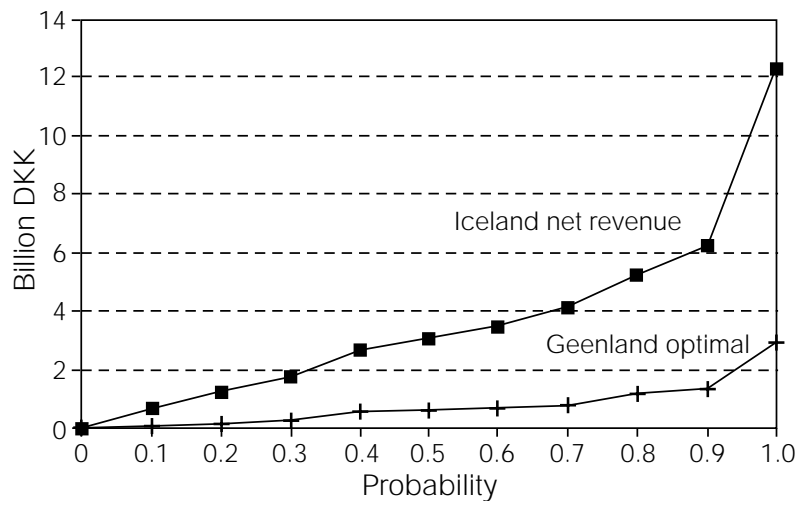

Fig. 6. A 20-year game in a non-equilibrium situation fishing the transboundary cod stock. Greenland Optimal: the revenue Greenland would obtain if it adopted the local optimal strategy. Iceland Net Revenue: the Iceland revenue under joint optimal fishing less the contribution to Iceland in case Greenland adopts the local optimal strategy.

agreement, than by applying her own local optimal fishery strategy, Iceland under such an agreement of DKK 100 million annually would have lost money in a little more than $30 \%$ of the cases.

If the agreement is only 5 years the risks are increased. Consider a 500 million DKK agreement (again DKK is 100 million annually). Now Greenland, as can be seen from Fig. 7, in a little less than $80 \%$ of the cases, would have done worse from such a transaction, whereas Iceland, in almost $60 \%$ of the cases, would have lost money.

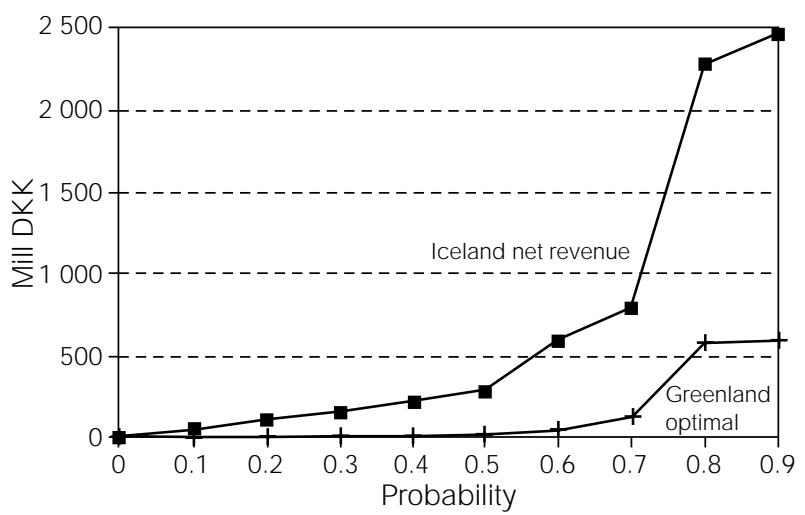

Fig. 7. A 5-year game in a non-equilibrium situation fishing the transboundary cod stock. Greenland Optimal: the revenue Greenland would obtain if it adopted the local optimal strategy. Iceland Net Revenue: the Iceland revenue under joint optimal fishing less the contribution to Iceland in case Greenland adopts the local optimal strategy.

\section{Discussion}

The simulations suggest it is advantageous to regard the offshore cod stock in West Greenland as a transboundary resource that should be shared and managed in cooperation between the joint owners, Greenland and Iceland.

The simulations suggest that both from an economic and a biological point of view, cooperation is more advantageous than independent management of the resources in the two areas. If the parties want to establish a long-term 
agreement, both the net revenue from the fishery and the gain from cooperation are dependent on the stochastic distribution of the future year-class strengths. If a strong year-class, i.e. a year-class strength equivalent to the strength of the 1984 yearclass, is recognized before an agreement is made, cooperation increases the total NPV of the cohort by DKK 1652 million compared to a noncooperative situation. Of this amount DKK 554 million may be considered costs to compensate Greenland and the remaining DKK 1098 million may be considered as the profit obtained by cooperation.

The considered problem is an externality problem. It is optimal to reduce the externalities only when the benefits from the reduction are greater than the connected costs. The costs of reducing the externality, i.e. the negotiation and enforcement costs, are regarded small in the present paper, laying the main emphasis on the benefit side. Consequently, the cooperative solution may not be implemented if the parties consider the uncertainties associated with the probability to obtain a surplus, too large.

It was assumed here that the Icelandic fishery is optimized on a long-term basis and that the immigrants are caught without applying any additional effort. The costs of the Icelandic fleet to catch the immigrating stock component are thereby neglected. Although it may be true that an increase in Icelandic catches may be due to an increase in catch-per-unit-effort rather than to increased effort, and effort and effort related costs therefore remain constant; the total costs may increase due to increased costs related to catch volume (e.g. insurance, transport, salt, handling and packaging materials) and catch value (e.g. sales provision and resource tax). This may result in over-estimation of the gain from cooperation.

Assuming that performers of a metier approaches the same level of competence in the long run, constant marginal cost is applied to the Greenland fishery. Therefore, maximizing the net revenue corresponds exactly to maximizing the resource rent. Even if increasing marginal costs are applied, however, the result of the analysis would not be changed significantly, although some of the net revenue, in this case, may be considered infra marginal rent (Anderson, 1982).

Most cod are exported from Greenland and Iceland. Therefore, there is no changes in the consumer surplus and prices can be assumed exogenous. The economic gain from cooperation may be overestimated, however, assuming constant prices, should exports from Greenland and Iceland affect world marked prices. Also, if Iceland is able to generate a higher value added than Greenland, inclination to cooperate may be influenced.

Sensitivity analyses indicate that the results of the present simulations are very robust with respect to the level of the social discount rate and to the size of the cohort. Even with a cohort size ten times as large as the 1984 year-class and a discount rate at $50 \%$, simulations imply that cooperation is advantageous and that all fishing should be undertaken in Icelandic waters.

Tagging data suggests that an offshore cod stock in West Greenland waters is dependent on inflows of eggs, larvae and juveniles from Iceland, and that the Icelandic stock component displays homing behaviour when they reach maturity. The simulations of the present study is based on the assumption that all cod at Greenland are of Icelandic origin and that they display homing behaviour when they reach maturity at about the age of 5 . As some mature cod are found in Greenland waters, although in small numbers, one or both of these assumptions may be violated.

The age dependent migration rates are estimated from data on maturity. As emigration of mature individuals would reduce both the average weight-at-age and the proportion of mature individuals of the remaining population, the migration rates are estimated from data from the Icelandic stock rather than from the Greenlandic stock. This procedure may overestimate the ratio of maturity in the stationary component of the Icelandic cod stock and, consequently, also overestimate the migration ratios and the advantage of cooperation.

In the underlying model of the present study, it is assumed that the Greenland component of the cod stock at Iceland does not contribute to the spawning in this area. Also this assumption is most likely violated as the migration is considered a spawning migration. The cooperation solution may therefore also be influenced by the stock recruitment relationship, which is not addressed by the present model.

\section{References}

ANDERSON, L. G. 1982. Optimal utilization of fisheries with increasing costs of effort. Can. J. Fish. Aquat. Sci., 39: 211-214.

ANON. 1968. CRC Standard Methematical Tables. 16th edition. Samuel M. Shelby (ed.). The Chemical Rubber Co., Cleveland, Ohio. 
MS 1992. Report of the North-Western Working Group. ICES C. M. Doc., Assess., 14 p.

MS 1993. Report of the North-Western Working Group. ICES C. M. Doc., Assess., 18 p.

BUCH, E., Sv. Aa. HORSTED, and H. HOVGÅRD. 1994. Fluctuations in the occurrence of cod in Greenland waters and their possible causes. ICES Mar. Sci. Sym., 198: 158-174.

CHRISTENSEN, S., and N. VESTERGAARD. 1993. A bioeconomic analysis of the Greenlandic shrimp fishery in the Davis Strait. Mar. Res. Economics, 8: 345-365.

CUSHING, D. H. 1982. Climate and fisheries. Academic Press Inc. (London) Ltd. ISBN 0-12-199720-0.

HANSEN, P. M., A. S. JENSEN, and Å. T. TÅNING. 1935. Cod marking experiments in the waters of Greenland, 1924-1933. Meddr. Komn. Dan. Havunders., Ser. Fisk., 10(1): 1-118.
HORSTED, Sv. Aa. MS 1990. Biological advice for and management of some of the major fisheries resources in Greenland waters. NAFO SCR Doc., No. 99, Serial No. N1834, 25 p.

MUNRO, G. R. 1991. The management of transboundary fishery resources: a theoretical overview. In: Essays on the economics of migratory fish stocks. Ragnar Arnason and Trond Bjørndal (eds.). Springer-Verlag.

NAFO. 1986-1991. NAFO Sci. Coun. Rep., 1986-1991.

RASMUSSEN, B. 1957. On the migration pattern of the West Greenland stock of cod. ICES Ann. Biol., 14: 124-124.

THOMPSON, W. F., and F. H. BELL. 1934. Biological statistics of the pacific halibut fishery. Rep. Int. Fish. (Pacific Halibut) Comm., 8, 49 p.

WOLFRAM, S. 1991. Mathematica: a system for doing mathematic by computer. 2nd. ed. Addison-Wesley Publ. Comp. Reading, Mass. 
